\title{
A RESIDUAL BIOASSAY TECHNIQUE TO INVESTIGATE SCALE CRAWLER SETTLEMENT ON KIWIFRUIT
}

\author{
R.H. BLANK, P.L. LO, G.S.C. GILL, and M.H. OLSON \\ MAF Technology, Private Bag, Whangarei
}

\section{SUMMARY}

A bioassay technique is described for testing the effectiveness of chemical residues to prevent settlement of armoured scale crawlers on kiwifruit leaves and fruit. A minimum of ten crawlers from a laboratory scale colony were seeded onto a $30 \mathrm{~mm}$ diameter leaf disc or fruit arena. Test samples were held for at least one day under optimum temperature and humidity for settlement. The percentage of leaf discs or fruit arenas which had more than one settled white cap were used to determine the residual effectiveness of chemical treatments with time. An illustration is presented using diazinon - treated fruit.

Keywords: Greedy scale, Hemiberlesia rapax, insecticides, bioassay

\section{INTRODUCTION}

Greedy scale, Hemiberlesia rapax (Comstock) and latania scale, H. lataniae (Signoret) are the two most important armoured scale (Hemiptera: Diaspididae) pests of kiwifruit (Berry et al 1989; Lo and Blank 1989). Insecticidal control of these scale pests on kiwifruit may be achieved in two different ways. The first is by direct contact of insecticide sprays onto settled scale. This type of control has been investigated by laboratory toxicity tests or by field efficacy tests (Blank et al 1985; 1991; Blank and Olson 1987).

The second form of control is through the activity of spray residues on the plant surface that prevents the establishment of scale crawlers. These crawlers may originate from mature scale already present on the kiwifruit (Hill et al 1986; Blank and Olson 1988) or by invasion of aerially dispersed crawlers from adjacent host plants (Blank et al 1990). Kiwifruit wood treated with lime sulphur was shown to give complete protection against crawler settlement for 36 days and almost full protection for a further 49 days before settlement occurred (Blank and Olson 1989). There have been no similar studies using kiwifruit leaves or fruit.

Other studies have investigated the combined effect of both contact and residual activity of insecticides and have often included longer term scale control using multiple insecticide applications (Kilsby and Steven 1983; Sale and Steven 1984; Tomkins et al 1986). In these studies the importance of the individual components contributing to control are unknown. There is a considerable amount of information already available on the residual properties of insecticides on kiwifruit (Holland et al 1984).

The prevention of scale settlement on fruit is important, as all fruit infested with scale, whether live or dead, are rejected for export. A balance also needs to be achieved between the frequency of insecticide applications and unwanted residues at harvest. Therefore, it is important to understand how long different insecticides afford protection from scale settlement on kiwifruit.

Many workers have developed techniques to investigate the residual toxicity of insecticides to mobile scale insects (Pfeiffer 1985; Morse et al 1986; Bellows et al 1988). However, none of these are appropriate for use with armoured scale on kiwifruit.

The objective of this study was to develop techniques which would enable the longevity of protection afforded by different chemicals on kiwifruit leaves and fruit to be determined.

Proc. 45th N.Z. Plant Protection Conf. 1992: 174-179 


\section{BIOASSAY TECHNIQUE}

Kiwifruit plants were sprayed with chemicals in such a way as to ensure thorough coverage. Chemicals may be applied using conventional airblast or hydraulic sprayers, or motorised knapsack sprayers for smaller (1-4 vine) plots. Alternatively, a Potter tower could be used to apply precise amounts of chemicals to leaf sections or fruit. Untreated and treated leaves or fruit were sampled at appropriate intervals following spray application. Scale crawlers from a laboratory colony were then seeded onto a test arena. Samples were held under conditions favourable for settlement. Survival was indicated by crawlers completing the spinning of a silk cover to become the first settled stage known as a white cap.

\section{Test arena}

The small size of the crawler and white cap stages $(0.1-0.2 \mathrm{~mm}$ diameter) meant that the seeding on and assessment procedures were carried out under a low power binocular microscope. It was essential to restrict the crawlers to a test arena as they moved rapidly and become difficult to relocate or were lost. A $30 \mathrm{~mm}$ diameter arena was found to be a suitable size for viewing under the microscope and allowed the settlement of 10-60 crawlers.

The leaf test arena was made by cutting a disc from a mature kiwifruit leaf. A flat uniform portion of leaf that included a side vein running through the middle of the disc was selected to ensure that preferred crawler settlement sites were available. Each leaf disc was then floated on water in the centre of a small container. The water acted as a barrier to the crawlers and also prevented the leaf disc from drying out. The upper surface of the leaf, which was preferred by the scale for settlement, was used as the test surface.

Several methods, including Stickem, water, and wax, were tested as barriers to crawlers on fruit. The most successful technique was to dip fruit into molten paraffin wax leaving approximately a $30 \mathrm{~mm}$ diameter area of uncoated fruit. This test arena was located on the shoulder of the fruit halfway between the calyx and the middle of the fruit on the narrow axis. Waxing 40 fruit took approximately 20 minutes. Seeding arenas

Greedy scale were reared on potatoes (cv. Desiree) and butternut squash in a controlled temperature room at $20 \pm 1{ }^{\circ} \mathrm{C}$. Under certain conditions, which have not yet been critically determined, mature scale produced masses of crawlers which coalesced to form a yellow 'bloom' on the highest points of the potatoes. Under these conditions several crawlers could be picked up at once using a fine camel hair art brush and deposited onto the test arena. Otherwise, crawlers were placed singly. A minimum of 10-15 crawlers was used per test arena with up to 60 being used when available. In any one trial, similar numbers of crawlers were used per test arena. Crawlers which were not active after seeding were removed and replaced. Seeding 15 crawlers onto 40 fruit can take from $1-2.5$, hours depending on the availability of crawlers.

\section{Settlement}

Leaf discs or fruit were held under conditions which enhanced crawler survival and encouraged settlement. Early studies showed crawlers and early settled white caps were vulnerable to desiccation. Preliminary studies also found leaf discs become infected with fungi if held for one or more days at the high humidity created inside a sealed plastic container.

In another study white cap settlement levels of $77,81,86$ and $89 \%$ were achieved after $1,2,3$ and 4 days respectively when leaf discs were held under continuous light at $20^{\circ} \mathrm{C}$. Levels of settlement were high even though relative humidity in the controlled temperature room was approximately $50-60 \%$. It therefore appears that when leaf discs were floated on water, sufficient humidity occurred close to the leaf surface to assist survival and settlement. This study also showed that time of assessment did not markedly influence results.

In contrast, crawler survival and settlement on fruit was found to be affected by humidity when held at $26^{\circ} \mathrm{C}$ for 24 hours (Table 1). Settlement was significantly $(\mathrm{P}<0.05)$ increased from 72 to $88 \%$ and, overall, survival was significantly $(\mathrm{P}<0.05)$ 
enhanced from $76-92 \%$ at 55 and $80 \%$ relative humidity respectively.

These results suggest that leaf discs should be held at $20^{\circ} \mathrm{C}$ and $50-60 \%$ relative humidity whilst fruit may be held at $20-26^{\circ} \mathrm{C}$ at $80 \%$ relative humidity. Assessments may be carried out 1-3 days after seeding, except where there is clear evidence that insufficient time has been allowed for settlement to occur. For example, after 1 day if live crawlers and live pre-settled white caps (silk cap incomplete) are present the final assessment should be made after 2 days.

TABLE 1: Effect of humidity on crawler settlement at $26^{\circ} \mathrm{C}$ on untreated fruit after 24 hours.

\begin{tabular}{|c|c|c|c|c|c|c|c|c|}
\hline \multirow[t]{3}{*}{ Fruit } & \multicolumn{4}{|c|}{$55 \%$ Relative humidity } & \multicolumn{4}{|c|}{$80 \%$ Relative humidity } \\
\hline & \multicolumn{2}{|c|}{ Crawler } & \multicolumn{2}{|c|}{ White cap } & \multicolumn{2}{|c|}{ Crawler } & \multicolumn{2}{|c|}{ White Cap } \\
\hline & Alive & Dead & Alive & Dead & Alive & Dead & Alive & Dead \\
\hline 1 & 1 & 2 & 6 & 1 & 1 & 1 & 9 & 0 \\
\hline 2 & 1 & 1 & 8 & 0 & 0 & 0 & 10 & 0 \\
\hline 3 & 0 & 4 & 7 & 0 & 0 & 1 & 9 & 0 \\
\hline 4 & 0 & 2 & 8 & 0 & 0 & 2 & 8 & 0 \\
\hline 5 & 1 & 2 & 6 & 0 & 1 & 0 & 8 & 0 \\
\hline mean & 0.6 & 2.2 & 7.0 & 0.2 & 0.4 & 0.8 & 8.8 & 0 \\
\hline SEM & 0.25 & 0.49 & 0.45 & 0.20 & 0.25 & 0.37 & 0.37 & 0 \\
\hline
\end{tabular}

\section{Assessment}

Immediately after insecticide application all crawlers will be killed by the residue. As the insecticide residue degrades, the proportion of crawlers that survive and develop white caps begins to increase. Some crawlers may commence to spin a silk cover but die before the white cap has been completed. These early - settled stages are not considered to be white caps.

Assessment of 40 fruit took 1 to 2 hours depending on whether crawlers were all dead, or if there was a need to assess a large number of white caps for mortality. Mortality assessment of white caps can be difficult unless they are held for several days to allow shrivelling and blackening of the normally plump yellow body to take place. It was considered preferable to use an assessment technique which did not rely on mortality assessment.

The assessment preferred in this study was to categorise each repeat (leaf disc or fruit arena) as either a positive or negative white cap settlement response. A positive response was one or more settled white caps. Given that some variability in chemical residue between repeats would be expected, it was important to have at least 10 repeats which gave a reasonable estimate of the proportion of positive responses.

\section{AN ILLUSTRATION}

The following experiment demonstrates the type of results that can be achieved using the bioassay technique. A diazinon (Diazinon 50W, $50 \mathrm{~g} / 100$ litres) spray was applied to kiwifruit using a motorised Solo knapsack. The effect of the diazinon residues on fruit on scale settlement was evaluated 2, 4, 6 and 8 days after application. The fruit in this trial were placed in water leaving a small dry arena for the crawlers. Three fruit became flooded on day 2 illustrating the problems of using water as a barrier.

Assessments were made 3-6 days after seeding areas with crawlers as an estimate of white cap mortality was required. Numbers of live and dead crawlers were also assessed but the data are not presented.

The consistently high white cap settlement on all untreated fruit gave a positive response in all cases (Table 2). White cap mortality on untreated fruit ranged from $1-3 \%$. A small proportion $(<12 \%)$ of mainly dead crawlers were also recovered from the untreated fruit. An atypical result was found on one untreated fruit (day 2, fruit 9) with 2 dead white caps and 20 dead crawlers.

Individual treated fruit responses were highly variable. Overall white cap mortality averaged 56,60, 43 and $27 \%$ at 2, 4, 6 and 8 days respectively after the diazinon 
application. Occasionally, all the crawlers were killed, but one or two white caps survived. For example, after 6 days, fruit number 15 had 24 dead crawlers and 2 live white caps.

TABLE 2: The effect of diazinon residues on white cap settlement on kiwifruit.

\begin{tabular}{|c|c|c|c|c|c|c|c|c|}
\hline \multirow{4}{*}{ Fruit } & \multicolumn{8}{|c|}{ Numbers of settled white cap } \\
\hline & \multicolumn{4}{|c|}{ Day 2} & \multicolumn{4}{|c|}{ Day 4} \\
\hline & \multicolumn{2}{|c|}{ Diazinon } & \multicolumn{2}{|c|}{ Untreated } & \multicolumn{2}{|c|}{ Diazinon } & \multicolumn{2}{|c|}{ Untreated } \\
\hline & Alive & Dead & Alive & Dead & Alive & Dead & Alive & Dead \\
\hline 1 & 0 & 1 & 17 & 0 & 2 & 20 & 45 & 0 \\
\hline 2 & 0 & 0 & 17 & 3 & 4 & 18 & 61 & 1 \\
\hline 3 & 2 & 8 & 43 & 0 & 10 & 15 & 23 & 0 \\
\hline 4 & - & - & 37 & 0 & 14 & 9 & 59 & 1 \\
\hline 5 & 5 & 3 & 41 & 4 & 2 & 21 & 53 & 1 \\
\hline 6 & 0 & 0 & 35 & 3 & 2 & 20 & 47 & 3 \\
\hline 7 & 3 & 0 & 110 & 1 & 1 & 7 & 35 & 1 \\
\hline 8 & 17 & 2 & 29 & 1 & 18 & 6 & 59 & 3 \\
\hline 9 & 0 & 3 & 0 & 2 & 0 & 19 & 70 & 2 \\
\hline 10 & 0 & 6 & 20 & 0 & 14 & 2 & 27 & 0 \\
\hline 11 & 0 & 1 & 25 & 0 & 18 & 7 & 41 & 0 \\
\hline 12 & 0 & 0 & 23 & 0 & 3 & 10 & 24 & 1 \\
\hline 13 & 0 & 11 & 39 & 0 & 2 & 10 & 42 & 1 \\
\hline 14 & - & - & 33 & 0 & 16 & 7 & 41 & 1 \\
\hline \multirow[t]{2}{*}{15} & - & & 24 & 0 & 15 & 9 & 44 & 0 \\
\hline & \multicolumn{4}{|c|}{ Day 6} & \multicolumn{4}{|c|}{ Day 8} \\
\hline 1 & 25 & 0 & 24 & 0 & 21 & 3 & 24 & 0 \\
\hline 2 & 25 & 0 & 25 & 0 & 20 & 0 & 34 & 0 \\
\hline 3 & - & - & 21 & 0 & 17 & 0 & 35 & 0 \\
\hline 4 & 0 & 25 & 34 & 0 & 18 & 0 & 23 & 0 \\
\hline 5 & 0 & 25 & 10 & 0 & 0 & 10 & 39 & 0 \\
\hline 6 & 25 & 0 & 33 & 0 & 20 & 3 & 33 & 0 \\
\hline 7 & 7 & 16 & 27 & 0 & 25 & 4 & 33 & 0 \\
\hline 8 & 0 & 16 & 30 & 0 & 0 & 24 & 22 & 0 \\
\hline 9 & 1 & 24 & 31 & 0 & 8 & 12 & 38 & 1 \\
\hline 10 & 18 & 4 & 28 & 1 & 19 & 7 & 25 & 0 \\
\hline 11 & 7 & 0 & 52 & 2 & 22 & 2 & 30 & 1 \\
\hline 12 & 25 & 2 & 22 & 0 & 7 & 12 & 27 & 0 \\
\hline 13 & 25 & 0 & 25 & 0 & 36 & 2 & 26 & 1 \\
\hline 14 & 10 & 15 & 27 & 0 & 33 & 1 & 25 & 0 \\
\hline 15 & 2 & 1 & 30 & 0 & 10 & 15 & 21 & 1 \\
\hline
\end{tabular}

A graphical presentation of results shows a gradual increase in the proportion of positive settlement on fruit against time (Figure 1). In this example the live white cap regression gave a better fit than did the total (live and dead) white cap regression. However, the assessment based on total white caps is experimentally the simplest technique to use, as it avoids problems involved in assessing white cap mortality.

To compare diazinon with other treatments, the medium Residual Settlement Time $\left(\mathrm{RST}_{50}\right)$ could also be estimated. Irrespective of the assessment method used, the residual activity of diazinon is shown to be short-lived with a $\mathrm{RST}_{50}$ of 4 days (live white caps) or less than 2 days (total white caps).

\section{DISCUSSION}

The development of this bioassay technique has been based on the positive white cap settlement response instead of the more complex and time consuming assessment of crawler and white cap survival, as well as white cap settlement. This has lead to a simplification in the procedures as the exact number of live healthy crawlers seeded 
onto each test arena need not be precisely known, as the fate of individual crawlers does not have to be accounted for. All we require is sufficient crawlers to test the suitability of the test arena for settlement. Furthermore, the interpretation and presentation of results is simplified as we only need to consider one variable instead of three.

The bioassay technique described here is currently being used to investigate how long chemicals protect kiwifruit from scale settlement. The results of these bioassays will be compared with chemical residue analyses. This information will be of value in refining spray recommendations and may also form the basis of a model to predict the biological activity of chemical residues under different conditions.

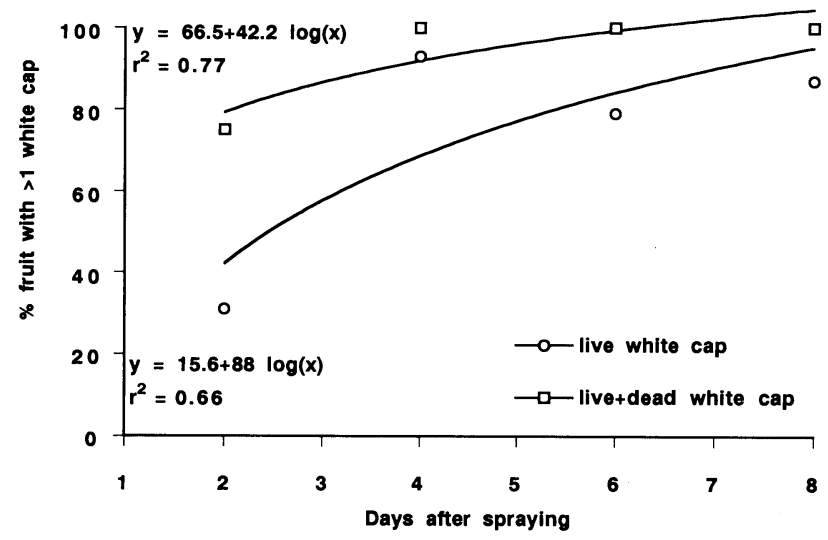

Fig. 1: The proportion of diazinon treated fruit on which white cap settlement occurred with time. The regression curves using live and total (live and dead) white caps are presented.

\section{ACKNOWLEDGEMENTS}

We would like to thank Mrs J.M. Kelly and Mrs N.B. Tapper for technical assistance.

\section{REFERENCES}

Bellows, T.S. and Morse, J.G., 1988. Residual toxicity following dilute or low- volume applications of insecticides used for the control of California red scale (Homoptera: Diaspididae) to four beneficial species in a citrus agroecosystem. J. Econ. Ent 81: $892-898$

Berry, J. A., Morales, C. F., Hill, M.G., Lofroth, B.J. and Allan, D.J., 1989. The incidence of three diaspid scales on kiwifruit in New Zealand. Proc. 42nd N.Z Weed and Pest Control Conf.: 182-186.

Blank, R.H. and Olson, M.H., 1987. Differential toxicological response of greedy scale stages to diazinon. Proc. 40th N.Z. Weed and Pest Control Conf.: 187190.

Blank, R.H. and Olson, M.H., 1988. Winter inspection of kiwifruit orchards for scale. Proc. 4lst N.Z. Weed and Pest Control Conf: 238-242.

Blank, R.H. and Olson, M.H., 1989. Lime sulphur for armoured scale and lichen control on kiwifruit. Proc. 42nd N.Z. Weed and Pest Control Conf.: 191-194.

Blank, R.H., Olson, M.H. and Lo, P.L., 1990. Armoured scale (Hemiptera: Diaspididae) aerial invasion into kiwifruit orchards from adjacent host plants. N.Z. J. Crop Hort. Sc. 18: 81-87.

Blank, R.H., Olson, M.H. and Waller, J.E., 1985. Screening pesticides for control of greedy scale on kiwifruit leaves. Proc. 38th N.Z. Weed and Pest Control Conf.: 219-222. 
Blank, R.H., Olson, M.H. and Waller, J.E., 1991. Relative efficacy of chemicals for dormant season control of armoured scale on kiwifruit. Proc. 44th N.Z. Weed and Pest Control Conf.: 75-79.

Hill, M.G., Allan, D.J., McKenna, C. and Steven, D., 1986. Monitoring greedy scale crawler activity on kiwifruit vines. Proc. 39th N.Z. Weed and Pest Control Conf.: 138-142.

Holland, P.T., McGhie, T.K. and Malcolm, C.P., 1984. Residual life of pesticides on kiwifruit. Proc. 37th Weed and Pest Control Conf.: 136-141

Kilsby, K.D. and Steven, D., 1983. Trials with pirimiphosmethyl/permethrin on kiwifruit. Proc. 36th N.Z. Weed and Pest Control Conf.: 107-110.

Lo, P.L. and Blank, R.H., 1989. A survey of armoured scale species (Hemiptera: Diaspididae) in kiwifruit orchards. N.Z. Entomol. 12: 1-4.

Morse, J.G., Bellows, T.S. and Iwata, Y. 1986. Technique for evaluating toxicity of pesticides to motile insects. J. Econ. Ent. 79: 281-283

Pfeiffer, D.G. 1985. Toxicity of avermectin B, to San Jose scale (Homoptera: Diaspididae) crawlers, and effects on orchard mites by crawler sprays compared with fullseason applications. J. Econ. Ent. 78: 1421-1424.

Sale, P.R. and Steven, D., 1984. Insect control trials on kiwifruit 1980-82. Proc. 37th N.Z. Weed and Pest Control Conf.: 125-129.

Tomkins, A.R., Holland, P.T., Phillip, K.C. and Malcolm, C.P., 1986. Dormant season control of greedy scale on kiwifruit. Proc. 39th N.Z. Weed and Pest Control Conf.: 133-137. 